\title{
Etnografando mercados: trabalho, sociabilidade e lazer no Ver-o-Peso ${ }^{1}$
}

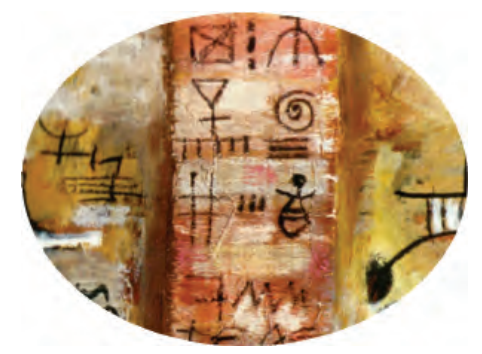

Tiago Luis Coelho Vaz Silva*

\section{Resumo}

O presente artigo é uma etnografia sobre o Ver-o-Peso, localizado em Belém (PA). Com base na organização e na dinâmica do mercado busca-se mostrar o cotidiano dos seus trabalhadores e de todos que o compõem, se configurando como local de trabalho, sociabilidade e lazer para os mais variados tipos de pessoas. Tais características fazem do mercado um instigante espaço de troca de bens materiais e imateriais.

Palavras-chave: Mercados e feiras; trabalho; sociabilidade; lazer; ver-o-peso.

\section{Abstract}

The present article is an ethnography about the Ver-o-Peso, located in Belém (PA). Based on the organization and dynamics of the market it aims to show of the daily lives of its workers and all its components, being configured as a place of work, sociability and leisure for a wide variety of people. These features make the market an instigating space for the exchange of material and immaterial assets.

\footnotetext{
"Mestre em Antropologia Social; professor da Universidade do Estado do Pará (UEPA). E-mail: tvazsilva@gmail.com
} 
Keywords: Markets and fairs; work; sociability; leisure; ver-o-peso.

\section{Introdução}

Sabe-se que desde a Escola de Chicago o modo de vida urbano passou a se constituir como objeto de reflexão para sociólogos e antropólogos. Fazer antropologia no meio urbano requer determinadas especificidades metodológicas, pois se trata de agrupamentos de grande escala, com elevado nível de divisão social do trabalho e número de papéis sociais. No entanto, é importante perceber que o modo de vida urbano sofre significativa influência do meio rural e vice-versa, uma vez que existe interação constante entre pessoas que transitam em ambos os espaços como, por exemplo, podemos notar para o Ver-o-Peso os traços característicos da presença "ribeirinha".

Nestes estudos, torna-se imprescindível observar a cidade e seus agentes com outros olhos, problematizando seus cenários e paisagens habituais, bem como, os costumes, as crenças e os valores dos indivíduos que compõem estes espaços, até então pensados sob certa ideia de familiaridade (MAGNANI \& TORRES, 2000). Contudo, essa familiaridade deve se constituir em objeto de reflexão permanente, para não incorrer em equívoco de naturalizar e estereotipar os costumes e os hábitos cotidianos, pois os mesmos podem ser reveladores de determinadas relações entre os indivíduos. Caso contrário, tais relações passarão despercebidas já que também fazem parte das representações do próprio pesquisador (VELHO, 1997).

Nesse artigo convido o leitor a fazer uma viagem etnográfica pelo Vero-Peso, mostrando a dinâmica e a organização do mercado, através do cotidiano dos seus trabalhadores e todas as outras pessoas que compõem o seu cenário, impregnado de valores e significados expressivos para sua gente.

\section{O Ver-o-Peso e sua gente}

O Ver-o-Peso é um mercado a céu aberto, situado frente à baía de Guajará, considerado por muitos a maior feira livre da América Latina. Seu

28 Somanlu, ano 11, n. 1, jan./jun. 2011 
cenário é bastante diversificado, sendo composto por edificações de ferro escocês, do início do século XX, além de uma extensa área de feira livre onde se comercializam produtos locais, regionais e itens do comércio em geral, com destaque para as barracas de ervas medicinais, de frutas e animais da Amazônia. A partir desse perfil é também local de trabalho, sociabilidade e lazer para os mais variados tipos de pessoas.

A feira é composta de vários lugares, o que faz dela um verdadeiro complexo com aproximadamente 26.500 metros quadrados e cerca de mil e quinhentas barracas e box(s), segundo dados da Secretaria Municipal de Economia de Belém (SECON, 2010-a). Em sua extensão, o complexo do Ver-oPeso é formado por dois mercados: Mercado de Ferro (Mercado de Peixe) e Mercado Francisco Bolonha (Mercado de Carne); pelo Solar da Beira; Feira do Açaí; além da feira a céu aberto. Também fazem parte três praças: Praça do Pescador, dos Velames e do Relógio. Devido à grande heterogeneidade do lugar em termos espaciais e humanísticos, compreender sua dinâmica requer uma multiplicidade de olhares sobre ele.

À medida que nos aproximamos das barracas de alimentação, um dos maiores setores da feira, é praticamente impossível não sentir os aromas da culinária paraense, expressa nos seus pratos típicos. Diversos tipos de pratos são servidos: peixe-frito com açaí, pato no tucupi, maniçoba, vatapá, caruru, tacacá; e refeições consumidas no dia a dia com mais frequência: sopa, caldo, carnes assada e cozida.

A maioria destas comidas "típicas" são o que podemos denominar de "comidas rituais" e não fazem parte da alimentação diária das pessoas, exceto o peixe frito e o açaí, tidos como mais comuns. Esses pratos típicos são, geralmente, associados a momentos festivos ou a épocas do ano como, por exemplo, o pato no tucupi e a maniçoba, refeições especiais no Círio de Nazaré. Assim, a popularização da comercialização dessas refeições na feira possibilita ao paraense, apreciador da culinária regional, comer as "comidas rituais" com um pouco mais de frequência; também, obviamente, está relacionada à questão do turismo que torna rentável esta atividade. 
Além de refeições, os feirantes comercializam diversos tipos de alimentos: mingau de tapioca, de milho, de arroz; café com leite ou simplesmente café; bolo de macaxeira e outros sabores; cuscuz; tapioca e lanches rápidos - salgados com sucos, chamados popularmente de "completo".

O setor de alimentação está dividido em dois blocos. Subindo poucos degraus de uma escadaria temos acesso à continuação deste setor, localizado as proximidades de um cais à beira-rio que se estende desde a Praça do Pescador até o Solar da Beira. Este outro bloco de alimentação também se caracteriza como um ponto de encontro, onde amigos e casais "tomam uma cervejinha" e conversam apreciando a paisagem à beira-rio ao som de música, em sua maioria, brega, tecno-brega, cúmbia, pagode e sertanejo ou assistindo a shows de bandas destes gêneros musicais em DVDs. Isso fica mais visível no final da tarde e ao anoitecer, quando diminui o fluxo de pessoas e o mercado assume um ar boêmio.

Pela manhã, a movimentação é grande no Ver-o-Peso, intensificandose por voltas das onze horas ao meio-dia, onde várias pessoas transitam pela feira. As vendas não se restringem às barracas e boxes, pois muitos feirantes itinerantes circulam por toda parte com os mais variados produtos. "Bicheiros" fazem o jogo do bicho; alguns saem oferecendo caranguejos vivos em paneiros ou caixas de geladeira, chamada por eles de "casco"; "sacoleiros" vendem sacolas para as pessoas carregarem suas compras; engraxates a procura de algum cliente; pessoas conduzindo bicicletas para vender o "completo"; camelôs oferecendo importados e pequenos produtos entre eles, pilhas, canetas e barbeadores. Também, alguns vendedores de frutas, verduras e temperos saem com seus "carros de mão" deslocando-se pelos bairros da redondeza como cidade velha e jurunas, parando em determinados períodos para vender seus produtos na feira. Todas essas pessoas estão trabalhando para conseguir sua renda diária.

Ufa! A movimentação é tão grande que chega a confundir os sentidos e impressiona aquele que não está acostumado. $\mathrm{O}$ aglomerado de pessoas pelas vias de circulação andando de um lugar para o outro, vendendo ou comprando mercadorias; o barulho dos ônibus misturados com o vozerio em alto e

30 Somanlu, ano 11, n. 1, jan./jun. 2011 
bom som, típico das feiras, pode passar a impressão, num primeiro instante, de um lugar confuso e desorganizado. Porém, como já haviam assinalado as antropólogas Marilu Campelo e Iara Ferraz (2000), todas essas práticas constituem os códigos e as normas do espaço, fazendo parte da sua estrutura organizacional.

No Ver-o-Peso a sensação é como se os sentidos ficassem mais apurados, as cores parecem "saltar aos olhos", os cheiros das frutas e temperos exalam seus aromas, além dos sabores das comidas que impregnam o paladar e proporcionam diferentes sensações olfativas e degustativas, características do mercado que dificilmente passam despercebidas.

Além das formas de venda já descritas, outra modalidade chama atenção: à venda "arreada". Esta modalidade consiste na oferta de mercadorias fora das barracas por pessoas não cadastradas pela Secon. Os produtos comercializados "arreados" ficam em lonas estendidas ao chão ou sobre papelões em pequenos caixotes de madeira ou de plástico, virados para baixo. Muitos estão concentrados na Praça dos Velames e a frente das barracas de frutas, enquanto outros se situam perto do Solar da Beira. Quem comercializa frutas estende seu "arreado" próximo às barracas de fruta, quem vende verduras, legumes e temperos, os colocam perto do setor que oferece esta espécie de produto, fazendo concorrência aos vendedores cadastrados no mercado.

As barracas de frutas encontram-se inseridas em um setor bastante diverso, chamado de "uns e outros", onde se comercializa desde farinha a artesanato regional. O setor está dividido em dois blocos. No primeiro achamos todas as qualidades de frutas: banana, laranja, manga, uva, abacate, maçã, abacaxi etc.; porém, são as regionais que possuem maior destaque: cupuaçu, bacuri, taperebá, muruci, uxi, pupunha e castanha-do-pará. As barracas de frutas compreendem boa parte deste setor, mas ele é muito variado e transitando poucos passos no seu interior nos deparamos com novos feirantes e outras mercadorias: mel, cereais, produtos de mercearia e descartáveis, farinha, camarão seco, pirarucu e alguns peixes salgados. Este espaço foi composto por pequenos setores dispostos de maneira contígua, parecendo até outra feira dentro do próprio Ver-o-Peso (CAMPELO \& FERRAZ, 2000). 


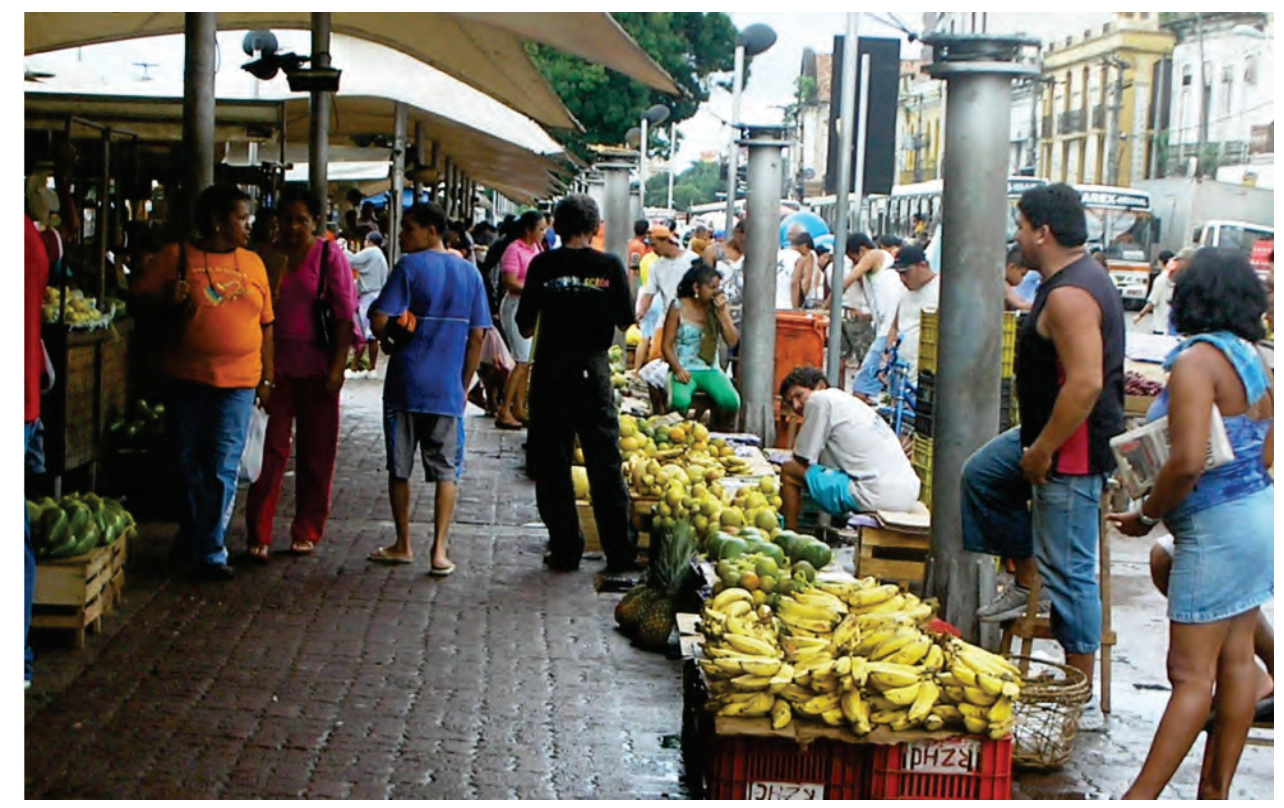

Foto 1. A feira retoma o seu fluxo característico após a chuva da tarde. Fonte: Pesquisa de campo.

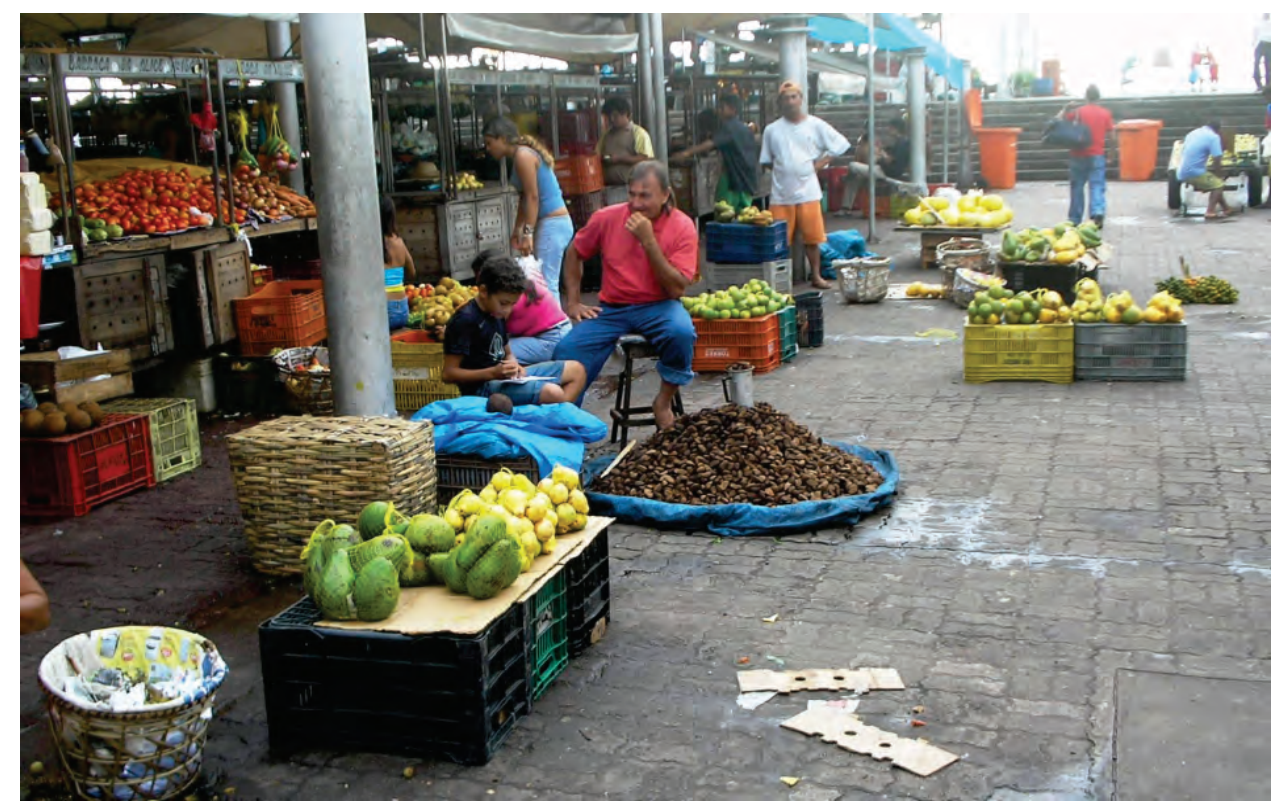

Foto 2. Vendedores de arreados na praça dos Velames. Fonte: Pesquisa de campo.

32 Somanlu, ano 11, n. 1, jan./jun. 2011 
Os feirantes que trabalham com mercearia vendem ingredientes, conhecidos como "misturas", para composição da feijoada e maniçoba: pé, orelha, toicinho e rabo de porco, charque, lingüiças, chouriço e bacon; além de mantimentos como feijão, arroz, macarrão, óleo de cozinha e sal.

Neste setor, além da numeração das barracas, os feirantes adicionam um nome ao seu comércio, como uma marca: "Barraca da Dina", "Barraca do Trindade"; outros mais criativos elaboram slogans como, por exemplo, os vendedores de mercearia: "Batatinha o Rei da Mistura", "Irmão o Príncipe da Mistura" e "Marcelo o Especialista da Mistura". É interessante notar a criatividade e as estratégias de venda utilizada pelos feirantes, um deles colocou sobre uma peça grande de charque a seguinte placa: "Charque Muito Lindo (Very Beautiful)", no intuito de atrair não apenas o freguês local, mas também o turista estrangeiro; além da irreverência dos seus anúncios imbuídos de duplo sentido: "Neste carnaval vamos comer bem charque"2, certamente fazendo alusão a atividade sexual e sua relação com a data festiva.

É possível perceber a existência de redes de comercialização interna de mercadorias na feira. Os comerciantes de polpa de frutas vendem seus produtos para os vendedores de lanches e sucos, os feirantes de farinha vendem-na para os que comercializam refeições, estes por sua vez vendem refeição para os feirantes de farinha e também compram carne dos açougueiros do Mercado Bolonha; instituindo uma ampla rede de comércio interno na feira. Além disso, alguns trabalhadores que mercanciam produtos do mesmo gênero, portanto concorrentes em potencial, ajudam-se mutuamente seja indicando aquele que dispõe da mercadoria procurada pelo freguês; seja reparando a barraca ou fazendo a venda para o parceiro quando ele precisa se ausentar momentaneamente; diminuindo a situação de tensão e estresse que envolve a relação de concorrência comercial - o que pressupõe a existência de outras formas de relações entre essas pessoas além da disputa mercantil.

Mal saímos da área destinada às mercearias e já estamos no local da farinha. Produto tradicional e básico da alimentação regional, na feira encontramos de vários tipos: farinha fina, média e grossa, farinha de farofa, farinha branca, farinha d'água, farinha seca, farinha surui e farinha de tapioca. Dali já 
se sente o cheiro forte vindo das barracas de pirarucu, piracui, aviu e camarão seco. A espera de clientes que comprem suas mercadorias, uns feirantes reúnem-se para conversar, outros passam o tempo jogando dama, porém todos atentos ao movimento, bastando um simples olhar de interesse do freguês que eles estão prontos para atendê-lo.

O Solar da Beira é o primeiro prédio no sentido Praça do Pescador/ Feira do Açaí, localizando-se praticamente no meio da feira. Construção modesta, diferente da imponência da arquitetura do Mercado de Ferro e do Mercado Bolonha, sua história está profundamente ligada ao Ver-o-Peso, onde durante muitos anos foi conhecido por Prédio das Mesas das Diversas Rendas ou Prédio da Recebedoria de Rendas, funcionando como sede em que se contabilizavam os proventos da Casa do Haver-o-Peso. Na década de 80, o prédio abrigou os comerciantes de artesanato e cerâmica da feira; atualmente funciona como ponto turístico e sede da administração do mercado.

Ao fundo deste prédio, se prolongando a parte de trás do setor de ervas medicinais e do Mercado de Ferro até próximo ao cais do porto, trabalhadores vendem todas as qualidades de hortigranjeiros, verduras, legumes e temperos. Atrás do Mercado de Ferro, algumas barracas de hortigranjeiros passam à impressão de que estão abandonadas ou desativadas para quem desconhece o local, devido ao contraste com o resto da feira, bastante movimentada. Porém, estão simplesmente fechadas pela manhã, pois seus permissionários trabalharam por toda a madrugada na venda de seus produtos.

Nosso percurso nos leva a um dos setores de maior destaque do Ver-oPeso: as barracas de ervas medicinais, síntese do universo simbólico da região amazônica. O comércio de ervas, banhos e "garrafadas" - a mistura de várias ervas maceradas e combinadas com algum líquido, vendido como poções - é realizado pelas "erveiras", nome pelo qual são conhecidas as mulheres que desenvolvem este ofício na feira.

As pessoas que trabalham com ervas são, em sua maioria, mulheres e tem o conhecimento e sabedoria sobre as plantas, repassadas por seus familiares ao longo de gerações, contribuindo para que tal atividade se constitua como um negócio de família no Ver-o-Peso. Suas plantas, raízes e as garrafa-

34 Somanlu, ano 11, n. 1, jan./jun. 2011 
das feita delas são apresentadas como solução para as diferentes mazelas sejam elas de natureza física, emocional ou espiritual. O preparo das poções requer conhecimento sobre as plantas e raízes, pois algumas delas são venenosas e se não cuidadas adequadamente podem ser fatais. Na sua composição passam por certos rituais de preparo: são lavadas, escaldadas e colocadas no "vinho", exigindo observância de preceitos antes de serem vendidas às pessoas, sendo que estas, por sua vez, devem utilizá-las com parcimônia.

Nas barracas de ervas pode-se encontrar desde cheiro do Pará ${ }^{3}$, óleos para o corpo e revigorantes sexuais até garrafadas contendo aranhas; cabeças e rabos de cobra; e genitálias do boto (macho e fêmea); uma verdadeira "boutique" de produtos naturais da Amazônia. Os produtos mais procurados são para tratar inflamações uterinas e banho para descarrego, bem como para tirar o "mau-olhado"4 e melhorar a situação financeira.

Portanto, basta falar qual o tipo de problema que as erveiras, sempre simpáticas, possuem na "ponta da língua" a solução para ele. Ademais, estas vendedoras oferecem seus produtos, utilizando o charme de seus olhares e sorrisos para atrair os clientes; ou até mesmo de uma forma mais persuasiva chamando-os a sua barraca, pegando e puxando, porém com delicadeza, para mostrar suas ervas e poções "milagrosas".

Nos dizeres das erveiras, este setor se constitui "de geração para geração", ficando sobre o controle dos parentes das famílias que o fundaram na feira, além de outras pessoas que, com o passar dos anos, conseguiram se estabelecer por lá. Conversando com algumas dessas mulheres, verificamos a predominância de duas famílias, o que já havia sido constatado na pesquisa de Marilu Campelo e Iara Ferraz (2000). Uma dessas famílias chega a concentrar mais de $60 \%$ dos trabalhadores no setor, configurando uma ampla rede de parentesco, havendo, ainda, pessoas que possuem parentes em mais de uma família, facilitando seu trânsito em ambas as partes.

Cruzando a Boulevard Castilho França, rua que margeia o Ver-o-Peso até o cais do porto, seguimos para o Mercado de Carne (Mercado Francisco Bolonha). Este mercado, construído em 1867, possui arquitetura em ferro de estilo art-nonveau, do início do século XX, que veio a substituir a estrutura 
original do prédio, feita de madeira. Símbolo da riqueza presenciada por Belém no período da borracha, várias pessoas circulam pelo Mercado de Carne, situado entre duas ruas, a Rua 15 de Novembro, no centro comercial; e a Boulevard Castilho França.

Nossa caminhada tem como destino o Mercado de Ferro (Mercado de Peixe), o mais importante referencial na paisagem urbana de Belém. Este prédio, todo em ferro, foi desmontado e trazido da Escócia pelos ingleses para a capital paraense, onde foi montado novamente, no ano de 1901. Também de estilo art-nouveau, destaca-se nesta construção as suas quatro torres em escama de zinco, registro de um período áureo vivenciado na cidade que pretendia ser a "Paris n'América" (DUARTE \& LUCARELLI, 2004).

$\mathrm{Na}$ parte externa do Mercado de Peixe, em todo o seu redor, existem várias lojas que desempenham diferentes atividades: farmácia, lanchonete, material de pesca, esportivo e elétrico, artigos de religião católica e afro-brasileira, barbearia, tabacaria e bar. Adentrando o Mercado de Peixe, logo sentimos o cheiro característico vindo do pescado e avistamos os box(s) com várias espécies de peixes frescos, tanto de rio quanto de mar: pescada amarela e branca, filhote, dourada, pratiqueira, serra, tamuatá, gurijuba, gó e muitos outros; também são ofertados mariscos: mexilhão, siri e camarões frescos, de água doce e salgada.

A movimentação é grande dentro do mercado, aumentando ainda mais nos finais de semana e feriados. Diariamente consumidores pesquisam e andam a procura do pescado que lhe convém, levando a mercadoria dos fornecedores que oferecem o preço mais em conta; sempre alertados, por meio de cartazes, de que devem "verificar o peso" antes de efetuar a compra. Na Semana Santa é intenso o fluxo de pessoas no local, período que este mercado chega a fornecer $33 \%$ do pescado comercializado na cidade (SECON, 2010-b).

Conhecendo o seu interior, observamos que os box(s) são todos padronizados e numerados; a comissão dos "peixeiros" disponibiliza bebedouro e balança digital para os fregueses pesarem suas compras. Mas, o que nos chamou atenção foi a grande quantidade de cartazes do Círio de Nazaré afixados nas suas paredes. Aliás, chegando pela entrada principal, encontram-se dois

36 Somanlu, ano 11, n. 1, jan./jun. 2011 
altares com a replica da imagem de Nossa Senhora de Nazaré, sendo que o primeiro situa-se próximo ao bebedouro e a balança digital; e o segundo, maior e mais vistoso, em um pequeno acesso elevado, que se chega através de uma escada. Devotos da Santa, no Círio os trabalhadores do Sindicado dos Peixeiros soltam fogos de artifício em sua homenagem, quando a berlinda percorre o trecho do mercado.

As atividades no Mercado de Peixe começam bem cedo, antes mesmo de o sol raiar, horário em que os carregadores ainda estão transportando o peixe do cais do porto para os box(s), onde a mercadoria será tratada e posta à venda. Os clientes que adquirem o pescado neste lugar começam a chegar perto das sete da manhã, se intensificando em torno das onze e se reduzindo à uma hora da tarde, quando o mercado fecha seus portões.

À tarde, no Ver-o-Peso, o movimento diminui em relação à manhã. Algumas barracas já se encontram fechadas e outros vendedores também já estão prestes a encerrar sua jornada de trabalho. No pôr do sol e ao anoitecer, a praça do pescador se torna ponto de encontro para namorados e amantes que apreciam a belíssima da paisagem da baía de Guajará, que se estende ao longo da feira. Nas suas proximidades existe um trapiche de onde chegam e saem diariamente barcos com pessoas e mercadorias para o município de Barcarena e outras ilhas às cercanias de Belém.

Assim, a feira vai adquirindo outras características, o espaço de trabalho também serve como local de sociabilidade e até mesmo de lazer, principalmente, quando se aproxima o término do expediente, para alguns, no final da tarde.

Próximo às barracas de camarão seco um grupo de trabalhadores conversa, outros jogam baralho; no Mercado de Carne pessoas reúnem-se para algumas partidas de dama e rodadas de dominó; os vendedores de mercearia e farinha contam suas piadas e fazem gozações uns dos outros; as mulheres das barracas de frutas aproveitam para pintar as unhas dos pés e das mãos; enquanto as erveiras "fofocam" sobre os mais diversos assuntos; além dos feirantes que dão uma rápida "passadinha" nas barracas dos seus parceiros, simplesmente, para um bom bate-papo.

Somanlu, ano 11, n. 1, jan./jun. 201137 
Nesses momentos as esferas do trabalho e do lazer confundem-se, tendo a jocosidade permeando o diálogo e as relações entre os trabalhadores. Também é comum que feirantes que se conhecem e já freqüentam o mercado há muitos anos chamem uns aos outros por apelidos e permitam-se determinadas brincadeiras que revelam certo grau de intimidade. São muitos os apelidos na feira, cada um mais inusitado do que o outro.

Esses pequenos acontecimentos no dia-a-dia do Ver-o-Peso, que na maioria das vezes passam despercebidos, demonstram a existência de um sistema mais amplo de trocas simbólicas que não se resume às trocas comerciais. Seus trabalhadores e todas as pessoas que possuem alguma relação com o mercado transmitem vivacidade ao lugar através de suas crenças, valores e experiências, narradas por meio das suas estórias e "causos"; através de laços de amizade, respeito, gentileza, confiança, expressas nas relações de dom e contra dom estabelecidas entre eles (MAUSS, 1974). Tais características fazem do mercado um instigante espaço de troca de bens materiais e imateriais.

À noite o fluxo de pessoas diminui ainda mais. As barracas de vestuários e eletroeletrônicos já se encontram fechadas. Alguma movimentação permanece nas barracas de lanches, bebidas e hortifrutigranjeiros que ficarão abertas até o amanhecer. Nas barracas que funcionam integralmente ocorrem trocas de turnos, geralmente gerenciadas por parentes. O Ver-o-Peso é uma feira fixa e mantêm-se aberta vinte e quatro horas, se diferenciando das feiras que funcionam apenas em certos dias - principalmente nos finais de semana e das itinerantes que se deslocam por ruas e bairros da cidade.

Mercado bastante heterogêneo e dinâmico, os personagens que compõem o Ver-o-Peso estão sempre se alternando de acordo com os locais e com os horários. No final da tarde uns fecham suas barracas e vão para suas casas esperar o dia seguinte: está encerrando-se a "feira do dia". Enquanto isso, outros estão chegando para a "feira da noite", dando início à sua jornada de trabalho cotidiana no mercado, que seguirá durante a madrugada como o fazem, por exemplo, alguns vendedores de hortigranjeiros, encerrando sua atividade de manhã cedo ou por volta do meio-dia para outros. Igualmente ao tempo social, o mercado também possui sua dinâmica própria.

38 Somanlu, ano 11, n. 1, jan./jun. 2011 
Com o avançar da noite a feira passa a ter um clima boêmio, pessoas conversam e se distraem escutando música e bebendo cerveja. Determinadas áreas do mercado são mais soturnas, possuem pouca iluminação e são perigosas para se transitar, onde ocorre, ainda, venda de drogas e prostituição. A Praça do Pescador já não é mais espaço para os namorados. Agora, indigentes e mendigos encontram-se deitados no gramado, em baixo de arbustos e nos bancos desta praça. A extremidade do mercado, na beira-rio, também não é um bom convite, pois quase não há movimentação por lá.

$\mathrm{Na}$ madrugada, a circulação de pessoas aumenta com a chegada dos produtos oriundos das ilhas que cercam Belém. Em poucos minutos a movimentação passa a ser tão intensa quanto pela manhã. O fluxo de pessoas e mercadorias inicia-se por volta das três horas e alcança seu auge entre quatro e meia e cinco da matina, se concentrando no Cais do Porto e na Feira do Açaí, onde se mercancia, respectivamente, o pescado e o fruto de mesmo nome da feira.

Diversas mercadorias também são comercializadas neste horário, como frutas, verduras, legumes e temperos. Mas, os produtos mais consumidos neste período são: o peixe e o açaí. Então, é seguindo o seu rumo que continuamos nossa caminhada.

Muitas espécies de peixe são comercializadas no Cais do Porto - ou na "pedra do Ver-o-Peso", como é conhecido popularmente. Os barcos que aportam neste local deixam o pescado armazenado em "urnas" ou "geleiras", nas próprias embarcações, até o momento de ser vendido. Os que primeiro chegam à doca atracam em locais estratégicos, considerados melhores para a comercialização, seja pela visibilidade; seja pela facilidade de desembarcar o peixe, pois em certos casos é preciso transitar por outras embarcações para retirar o pescado. Os barcos atracados ali conferem cores e textura bastante peculiares ao cenário amazônico.

O pescado chega de várias localidades, das ilhas que contornam a cidade e de lugares mais distantes, situados na região do salgado - litoral nordeste do estado do Pará, onde as águas dos rios interagem com o oceano. O pescado vendido neste horário tem como destino a revenda no Mercado de Peixe, em 
outras feiras e comércios de Belém e até mesmo em outros Estados. O volume diário de pescado comercializado na "pedra" varia entre 80 a 150 toneladas (SECON, 2010-b), caracterizando o espaço como um importante setor de abastecimento deste gênero para a capital paraense e cidades adjacentes.

Alguns pescadores possuem a venda certa, ou seja, já chegam com sua mercadoria encomendada por clientes, restando apenas ao comprador conferir a qualidade do pescado e realizar o pagamento, para concretizar o negócio e efetuar a retirada do produto. Outros pescadores ainda não têm a venda certa e vão à busca de consumidores para sua mercadoria. Eles armazenam em caixotes de isopor com gelo uma pequena parte de seu pescado para que fique à mostra, esperando a chegada de clientes.

Em questão de instante, o então consumidor, pode vir a ser o novo comerciante do pescado comprado há pouco: estamos falando do "balanceiro". O balanceiro é uma espécie de atravessador que atua na "pedra" comprando a mercadoria dos pescadores para revendê-la ao Mercado de Peixe e a outros clientes, tirando sua margem de lucro com o "negócio do peixe". Alguns deles trabalham por comissão para os donos dos barcos e recebem $6 \%$ a $7 \%$ do valor em transação. Hábeis negociadores, estão constantemente atualizando seus vínculos comerciais e de amizade com os pescadores, seus fornecedores. Prática comum, na "pedra" várias pessoas se dedicam a esta modalidade de serviço altamente rentável, procurando um pescado de qualidade a um preço razoável, com a finalidade de revenda.

O pescado que será comercializado no próprio Ver-o-Peso é levado por carregadores para o Mercado de Peixe, para o box do comerciante que o comprou, onde será lavado e preparado para a venda no mesmo dia, por volta das sete horas, quando aumenta o fluxo de pessoas naquele mercado. Os demais pescados são levados para veículos particulares a quem interessou a compra. O deslocamento do pescado é realizado por vários carregadores que oferecem seu serviço. Eles carregam o peixe em caixotes sobre suas cabeças e recebem por cada "carreto" que fazem - transporte da mercadoria ao seu destino - pago pelos comparadores do peixe.

40 Somanlu, ano 11, n. 1, jan./jun. 2011 
Seja em dia de madrugada enluarada ou chuvosa, a movimentação é intensa na "pedra". Ocorre um vai e vem de pessoas circulando neste espaço, alguns a procura de clientes para vender seu pescado; "viradores" recebendo alguns trocados para virarem o pescado depois de pesado na balança; muitos oferecendo seus serviços de carregador; enquanto outros já conseguiram ocupação e transitam para lá e para cá com o caixote na cabeça. Ainda, algumas pessoas se reúnem numa pequena conversa, fazendo uma pausa para tomar um café preto ou café com leite, acompanhado de pão, bolacha ou tapioca.

A circulação é tão grande que é comum escutar os carregadores falarem: "ta pingando! Ta pingando!", ou seja, mencionando para aqueles que se interpõem no seu caminho atrapalhando o deslocamento do caixote, que o peixe está escorrendo, mas, também, que o caixote está pesado. Neste horário, quem fica parado corre o risco de levar um esbarrão e quem "dorme no ponto" pode ficar sem a carteira.

Perto do Cais do Porto avistamos a Praça Siqueira Campos, mais conhecida como Praça do Relógio. Esta praça também está inserida no conjunto espacial denominado de "Complexo do Ver-o-Peso". No seu centro encontrase um grande relógio, datado de 1931, construído em ferro de estilo liberty; fabricado pela empresa escocesa MacFarlane \& Co, que havia fornecido as outras duas edificações metálicas para Belém, testemunhando, assim, em momentos diferentes, a construção das arquiteturas em ferro na cidade (DUARTE \& LUCARELLI, 2004).

Nosso percurso pelo Ver-o-Peso está para findar-se à medida que nos aproximamos da Feira do Açaí, nossa última paragem. A Feira do Açaí, como seu próprio nome já indica, é o local onde se comercializa o açaí trazido das ilhas que cercam Belém e abastecem-na deste produto. Na madrugada esta feira é tão agitada quanto à "pedra", concentrando outras pessoas em torno de outra mercadoria: o açaí, item tradicional na alimentação paraense. Todos os dias vários "ribeirinhos" chegam nas suas embarcações e aportam na feira para vender o fruto.

Muitos são os trabalhadores que se dedicam a carregar o fruto armazenado em paneiros, cobertos com folha de bananeira nos dias de chuva. O 
produto é levado pelos carregadores em carros de mão ou sobre a cabeça, que ganham por paneiro transportado, pago pelo dono da mercadoria.

$\mathrm{O}$ açaí mercanciado na feira será revendido em vários pontos da cidade. Os paneiros são colocados por seus donos em lugares estratégicos, sendo deixados à mostra para serem vendidos. A preferência é pelo açaí vindo das ilhas mais próximas, por ser colhido e posto a venda no mesmo dia, o que lhe confere qualidade verificada na cor, na textura e no sabor do fruto depois de batido. A lógica da venda do açaí é semelhante à do pescado, alguns trabalhadores já têm o seu açaí encomendado, enquanto outros ainda vão à busca de clientes para a sua mercadoria.

Igualmente o setor de alimentação, algumas barracas vendem lanches e café da manhã, com várias qualidades de tapioca para acompanhar. As demais barracas destinam-se ao comércio de cerveja, atraindo um grande número de pessoas populares para a feira, antes do início da venda do açaí. Muitas dessas pessoas procuram a feira não para trabalhar, mas para se distrair e confraternizar com seus amigos ao embalo de muita música e dança. A madrugada de sexta-feira para sábado é o dia mais agitado, os permissionários das barracas que vendem cerveja contratam bandas para animar o lugar e a festa "corre solta", fazendo com que alguns comerciantes de açaí adquiram dívidas com os donos dos bares antes mesmo de venderem sua mercadoria.

Assim é a alvorada no Ver-o-Peso. O dia está apenas começando, porém muito já se fez nestas poucas horas. Os trabalhadores e os boêmios da "feira da noite" vão para suas casas e retornarão no dia seguinte, enquanto muitos outros estão chegando para iniciar sua jornada de trabalho. Mais um dia na rotina do Ver-o-Peso, assim as relações vão sendo construídas e atualizadas pelos feirantes e todas as pessoas que, de alguma forma, vivenciam o seu cotidiano e transmitem vivacidade ao local, diariamente deixando parte de si no mercado e levando parte dele consigo.

\section{Considerações finais}

Nestas poucas linhas, procurei realizar uma descrição mais fina das relações que constituem o Ver-o-Peso, mostrando etnograficamente um pou-

42 Somanlu, ano 11, n. 1, jan./jun. 2011 
co do seu cotidiano e das pessoas que nele trabalham. Através da imersão na lógica que orienta as relações no mercado, busquei traçar um panorama geral, mas não superficial, para assim produzir uma interpretação a respeito do modus vivendi do seu universo (GEERTZ, 1997).

Principal cartão-postal de Belém, o Ver-o-Peso é significativo tanto para a economia quanto para a cultura da região, não só pela representatividade desse lugar na vida da cidade, mas, também, pela representatividade da população que por lá trabalha e circula. Ao longo de três séculos, o Ver-o-Peso não foi construído apenas fisicamente, mas, também, no plano da representação social, elaborada pelos próprios trabalhadores do mercado e pelos moradores da cidade.

Tais características fazem deste mercado um instigante lugar sociológico, bastante significativo no imaginário regional, pois não se restringe às trocas comerciais de compra e venda de produtos - o que se presume ser a sua função. Mais que isso, as relações que se estabelecem no Ver-o-Peso perpassam as trocas de bens materiais e penetram em esferas permeadas de solidariedade e reciprocidade, que envolve amizade, confiança, camaradagem, jocosidade etc., configurando-o num mercado de bens simbólicos.

\section{Notas}

${ }^{1}$ Este artigo é uma versão modificada de um capítulo da dissertação de mestrado intitulada "Vera-cor: um estudo sobre as relações raciais no mercado do Ver-o-Peso em Belém (PA)”.

${ }^{2}$ Nas conversas populares, principalmente nas piadas, o termo charque é usado para fazer referência ao órgão sexual feminino.

${ }^{3}$ O cheiro do Pará ou simplesmente "cheiro" é produzido a partir da raspagem de algumas raízes aromáticas até assumirem forma de um pó de cor marrom, embalado em pequenos sacos plásticos amarrados com fita é usado para perfumar roupas e ambientes.

${ }^{4}$ Concepção que faz parte das representações sociais da cultura amazônica, possuindo conotação de inveja e quebranto - embora, com denominações análogas, seja uma crença encontrada em muitas sociedades. 


\section{Referências}

CAMPELO, Marilu M. \& FERRAZ, Iara. Inventário Histórico, Sociocultural, Arquitetônico e Ambiental do Complexo do Ver-o-Peso. Departamento de Patrimônio Histórico (DEPH), Fundação Cultural do Município de Belém (FUMBEL), 2000 .

DUARTE, Cristóvão \& LUCARELLI, Francesco. Belém. Um percurso ao longo de quatro séculos. Patrimônio da Humanidade. 2004.

GEERTZ, Clifford. "Do ponto de vista dos nativos": a natureza do entendimento antropológico. In: O saber local: novos ensaios em antropologia interpretativa. Petrópolis, RJ: Vozes, 1997.

MAGNANI, José Guilherme C. \& TORRES, Lílian de Lucca. Na Metrópole. Textos de Antropologia Urbana. São Paulo: Edusp, 2000.

MAUSS, Marcel. Ensaio sobre a Dádiva. Forma e Razão da Troca nas Sociedades Arcaicas. In: Sociologia e Antropologia. São Paulo: EPU / Edusp, 1974.

SECRETARIA MUNICIPAL DE ECONOMIA DE BELÉM. Situação de Ocupação nas Feiras Municipais de Belém. Divisão de Controle Técnico do Departamento de Feiras, Mercados e Portos. DCT/DFMP/SECON, 2010-a.

Quantidade de Produtos comercializados nos Mercados Municipais. Divisão de Controle Técnico do Departamento de Feiras, Mercados e Portos. DCT/ DFMP/SECON, 2010-b.

VELHO, Gilberto. Observando o familiar. In: Individualismo e Cultura: notas para uma antropologia da sociedade contemporânea. Rio de janeiro: Zahar, 1997. 